\title{
RHINOLOGY
}

\section{Development of a questionnaire to investigate socio-cultural differences in the perception of smell, taste and flavour}

\author{
Sviluppo di un questionario per indagare le differenze socio-culturali nella percezione \\ di olfatto, gusto e sapore \\ Eleonora M.C. Trecca ${ }^{1,2}$, Francesca Fortunato ${ }^{3}$, Matteo Gelardi', Paolo Petrone ${ }^{4}$, Michele Cassano ${ }^{1}$ \\ ${ }^{1}$ Department of Otolaryngology, University Hospital of Foggia, Foggia, Italy; ${ }^{2}$ Department of Maxillofacial Surgery and \\ Otolaryngology; IRCCS Casa Sollievo della Sofferenza; San Giovanni Rotondo (FG), Italy; ${ }^{3}$ Department of Medical and Surgical \\ Sciences, University of Foggia, Foggia, Italy; ${ }^{4}$ Department of Otolaryngology, Di Venere Hospital, Bari, Italy
}

\begin{abstract}
SUMMARY
Objectives. Clinical experience and daily life indicate that the importance of smell, taste and flavour is variable among individuals. Therefore, the aim of this research was to develop a questionnaire to investigate the importance attributed to smell, taste and flavour and socio-cultural differences among individuals.

Methods. Cross-cultural adaptation of the questionnaire was executed by two professional translators and one bilingual investigator and pre-tested on a pilot group of 25 subjects with normal smell and taste abilities. The final version of the questionnaire was sent by e-mail to 850 healthy subjects. The Google form consisted of three parts: "The importance of olfaction" developed by Croy et al. in 2010, "The importance of taste and flavour" developed by our team and a section to collect demographic data. The questions were classified into "association", "application", "consequence" and "aggravation”. Statistical differences were assessed using $t$-test with $\mathrm{p} \leq 0.05$. Correlations were calculated using Spearman's test. Internal consistency was assessed using the Cronbach's Alpha, while test-retest reliability was analysed by calculating the Intraclass Correlation Coefficients (ICC2k).

Results. The questionnaire received a non-response rate of $10.7 \%$. Calculation of Cronbach's alpha showed good internal reliability $(\mathrm{a}=0.87)$. Test-retest evaluation was satisfactory for all subscales, with an overall ICC2k $=0.84$ (CI 0.79-0.89). Statistical analysis showed that smell, taste and flavour appeared to be more important for women when compared to men $(\mathrm{p}<0.001)$. No statistical differences were seen between individuals with various educational background ( $p>0.05)$, and the importance of smell $(r=0.16 ; p<0.01)$, taste and flavour $(r=0.08 ; \mathrm{p}<0.05)$ did not decline with age.

Conclusions. The development of this original test provides an overview into the importance of smell, taste and flavour among individuals. Although further research is needed, it can help in the evaluation and investigation of aspects that influence people to seek medical attention in the presence of sensory alterations.
\end{abstract}

KEY WORDS: olfaction, taste, olfactory disorders, quality of life, statistics

\section{RIASSUNTO}

Obiettivo. L'esperienza clinica e la vita quotidiana mostrano come l'importanza attribuita al senso dell'olfatto, del gusto e del sapore siano variabili nella popolazione. L'obiettivo di questo studio è stato, pertanto, quello di sviluppare un questionario per indagare l'importanza attribuita a questi sensi e le differenze socioculturali esistenti tra gli individui. Metodi. L'adattamento interculturale del questionario è stato eseguito da due traduttori professionisti e un ricercatore bilingue e pretestato su un gruppo pilota di 25 soggetti con normali capacità olfattive e gustative. La versione finale del questionario è stata inviata via e-mail a 850 soggetti sani. Il Google form era composto da tre parti: "L'importanza dell'olfatto" (Croy et al., 2010), "L'importanza di gusto e sapore" creato dal nostro gruppo, e un modulo per l'inserimento dei dati demografici. Le domande sono state suddivise in 4 classi: "associazione”, "applicazione", "conseguenza” e "gravità". Per l'analisi sta-
Received: March 25, 2020

Accepted: January 24, 2021

\section{Correspondence}

Eleonora M.C. Trecca

University Hospital of Foggia, Department of Otolaryngology, viale Pinto 1, 71122 Foggia, Italy

E-mail: eleonora.trecca@unifg.it

Funding

None.

Conflict of interest

The Authors declare no conflict of interest.

How to cite this article: Trecca EMC, Fortunato F, Gelardi M, et al. Development of a questionnaire to investigate socio-cultural differences in the perception of smell, taste and flavour. Acta Otorhinolaryngol Ital 2021;41:336-347. https:// doi.org/10.14639/0392-100X-N0766

( ) Società Italiana di Otorinolaringoiatria e Chirurgia Cervico-Facciale

\section{(c) (1) $(2)$}

This is an open access article distributed in accordance with the CC-BY-NC-ND (Creative Commons Attribution-NonCommercial-NoDerivatives 4.0 International) license. The article can be used by giving appropriate credit and mentioning the license, but only for non-commercial purposes and only in the original version. For further information: https:// creativecommons.org/licenses/by-nc-nd/4.0/deed.en 
tistica è stato utilizzato il test $t$ considerando come significative differenze con $p \leq 0,05$. Le correlazioni sono state calcolate con il test di Spearman. La coerenza interna è stata valutata utilizzando l'Alpha di Cronbach, mentre l'affidabilità del test-retest è stata analizzata calcolando i coefficienti di correlazione intra-classe (ICC2k).

Risultati. Il tasso di non risposta del questionario è stato pari al 10,7\%. Il calcolo dell'Alpha di Cronbach ha evidenziato una buona affidabilità interna $(a=0,87)$. Inoltre, la valutazione del test-retest è stata soddisfacente per tutte le scale, con un ICC $2 \mathrm{k}$ complessivo pari a 0,84 (CI 0,79-0,89). L'analisi statistica ha evidenziato che: olfatto, gusto e sapore sono risultati più importanti per le donne rispetto agli uomini $(p<0,001)$; non sono state evidenziate differenze statisticamente significative tra individui con diversi titoli di studio $(p>0,05) ;$ l'importanza attribuita all'olfatto $(r=0,16 ; p<0,01)$, così come quella al gusto e al sapore $(r=0,08 ; p<0,05)$, non è diminuita con l'aumentare dell'età degli intervistati.

Conclusioni. Lo sviluppo di questo nuovo questionario fornisce una panoramica completa sull'importanza attribuita al senso dell'olfatto, gusto e sapore e sulle differenze socio-culturali esistenti tra gli individui. Sebbene ulteriori studi siano necessari, potrebbe essere di aiuto nel comprendere quali aspetti influenzano gli individui nel cercare o meno una consulenza medica in presenza di alterazioni sensoriali.

PAROLE CHIAVE: olfatto, gusto, disturbi olfattivi, qualità della vita, statistica

\section{Introduction}

The use of questionnaires and clinical E-Surveys has become increasingly popular in medicine in the last few years, not only for research purposes, but also as diagnostic instruments. In the field of smell and taste disorders, subjective patient-reported olfactory assessment should be undertaken as a first level evaluation before proceeding with psychophysical olfactory tests ${ }^{1}$. Validated questionnaires and recognised forms of assessment exist in rhinology; they predominantly focus on sinonasal symptoms ${ }^{2}$, olfactory dysfunction and quality of life ${ }^{3}$, while giving more limited attention to taste complaints. Another type of questionnaire was developed by Croy et al. ${ }^{4}$ to provide a gauge of the individual importance of olfaction. Clinical experience and daily life show that the consideration of smell, taste and flavour varies among individuals. Interestingly, the importance of olfactory and gustatory function seems to vary not only within the general population, but also among patients with sensory impairment, who may or may not choose to pursue medical counselling 5 .

Therefore, the aim of this research was to develop a questionnaire to investigate the importance attributed not only to the sense of smell, but also to taste and flavour, and the socio-cultural differences among individuals.

\section{Materials and methods}

The study was conducted from June 2017 to March 2018 and was compliant with the Checklist for Reporting Results of Internet E-Surveys (CHERRIES) ${ }^{6}$. The Institutional Review Board of the University of Foggia Department of Otolaryngology approved this study. The questionnaire was translated into Italian and English and uploaded to Google Drive.

\section{Inclusion and exclusion criteria}

Recruitment was directed to male and female subjects aged $\geq 18$, with intact reading comprehension abilities and normal cognitive function [mini mental state examination (MMSE) score $\geq 26$ for subjects aged between 18 and 64 years and $\geq 24$ for subjects older than $65^{7}$ ]. Subjects assessed the severity of their nasal symptoms by answering the Sino-Nasal Outcome Test (SNOT-22) questionnaire in order to limit the possibility of any pre-existing sino-nasal disorder that might influence the chemical senses of the population; subjects with a baseline score $\leq 10^{8}$ were consequently included.

There were no exclusion criteria related to sex, race, gender or ethnicity, while subjects meeting any of the following criteria were excluded:

- history of Ear, Nose and Throat (ENT) diseases or preexisting smell/taste disorders;

- previous airway surgery (i.e., septoplasty, turbinoplasty, sinus surgery etc.);

- presence of upper respiratory tract infection (URTI);

- history of neuropsychiatric disorders (i.e., Parkinson's disease, Alzheimer's disease, multiple sclerosis, depression, eating disorders etc.);

- previous major head trauma;

- history of significant comorbidities, such as severe hypertension, poorly controlled diabetes mellitus, rheumatic or autoimmune disease;

- concurrent treatment or medication that may interfere with olfactory/gustatory function;

- history of drug or alcohol abuse;

- history of smoking 20 or more cigarettes/day ${ }^{9}$.

\section{Development of the questionnaire}

Cross-cultural adaptation of the questionnaire was executed by two professional translators and one bilingual investigator speaking Italian and English. Three Otolaryngologists, well acquainted with the topic involved, further improved the preliminary version obtained. A new version including all the suggestions was forwarded to the translators to execute the back-translation into Italian. Finally, the expert group developed a consensus version of the instrument ${ }^{10}$. 
As a last step, the tool was pre-tested on a pilot group of 25 subjects with normal smell and taste abilities confirmed by Sniffin' sticks and taste strips tests (Burghart ${ }^{\circledR}$ ) who fulfilled the inclusion criteria mentioned in the previous section to check for comprehensibility, redundancy and consistency of its items, including technical usability and functionality of the electronic platform.

The Google form consisted of three screens presenting the following questionnaires:

1. "Importance of olfaction" (IO-Q), developed by Croy et al. ${ }^{4}$ to evaluate the subjective importance attributed to the sense of smell (Tabs. I, II). For this questionnaire an Italian version validated by the Italian Academy of Rhinology (IAR) already existed and was adopted.

2. "Importance of taste and flavour" (ITF-Q), created by our group to evaluate the subjective importance attributed to taste and retronasal smell (Tabs. I, II).

3. "About you", a section for collecting demographic data (age, sex, nationality, education).

Based on the questionnaire by Croy et al. ${ }^{4}$, the items in the questionnaire "The importance of taste and flavour" (ITF-Q), were classified into four groups: "association" with sensations, "application" of the sense, ability to draw "consequences" from the olfactory and gustatory perception, and tendency to "aggravate" the importance of sensory loss. The first and second page consisted of 18 personal statements referring to one of the four mentioned subscales. The subjects attributed a score of 1 to 4 to indicate how much they agreed with the statement ("I totally agree" to "I totally disagree"). They were unaware of which scale the items belonged to. The third page consisted of a simple module in which the subject manually entered his or her age, country of origin, sex and education level.

After a preliminary meeting, during which eligibility of individuals to participate was established, informed consent was obtained and instructions and purpose of the research explained, the link was sent by e-mail to a sample of 850 people. The cohort comprised health workers, university and college students including international/exchange students, visitors to our University Hospital or patients' relatives who consented to be enrolled in this study. The "jellybean flavour experiment" was used to explain the not intuitive difference between taste and flavour to participants during the preliminary meeting [e.g.: close your eyes, pinch your nose with your hand and put a jellybean in your mouth. You should be able to perceive the taste (i.e., sweet), but only if you release your hand, will you be able to distinguish the correct flavour (i.e., strawberry)]. Before submitting the questionnaire, a mandatory completeness check highlighted the missing response items. Answers were automatically captured and stored in an electronic spread- sheet (Excel, Microsoft, 2011). In order to prevent multiple entries from the same individual, users were required to register first. The username was stored together with the survey results and later eliminated. The spreadsheet was stored and protected by unique passwords and kept on a secure, restricted network drive. Only the principal investigator and authorised study personnel had access to the files. No incentives were offered to complete the survey.

\section{Reproducibility of the questionnaire}

The reproducibility of the questionnaire was evaluated using internal consistency and test-retest reliability. Internal consistency was considered acceptable in case of Cronbach's alpha values between 0.7 and 0.9 . Additionally, 50 patients in the study group were randomly selected for assessment of test-retest reliability. In this cohort, the questionnaire was administered twice, after an interval of one month, without any possibility for participants to look at the answers given the first time. Test-retest reliability was assessed through Intraclass Correlation Coefficients (IC$\mathrm{C} 2 \mathrm{k}$ ) and considered acceptable with a minimum test-retest correlation coefficient of 0.7 .

\section{Statistical analysis}

Descriptive statistics were performed to characterize responses to the survey. Qualitative data were summarised as percentages. The assessment of significant differences across the means of continuous variables relied on t-tests for independent samples, with those values with $\mathrm{p} \leq 0.05$ were considered significant. To assess the distribution of the variables, Bartlett's test was used. The correlations were calculated using the Spearman test and Spearman's rho was also calculated. Internal consistency was assessed using Cronbach's alpha, while test-retest reliability was analysed by calculating the ICC $2 \mathrm{k}$. All analyses were performed using STATA-MP software, version 15 for Mac OS X.

\section{Results}

Overall, 759 of 850 subjects answered the questionnaire with a non-response rate of $10.7 \%$. Calculation of Cronbach's alpha showed good internal reliability $(\mathrm{a}=0.87)$. Test-retest evaluation was also satisfactory for all the subscales, with an overall ICC2k =0.84 (CI 0.79-0.89).

Of the responders, $460(60.6 \%)$ were female, $299(30.4 \%)$ were male, $508(66.9 \%)$ were college graduates, 231 $(30.4 \%)$ were high-school graduates and $20(2.7 \%)$ were secondary school graduates. By country of origin, 653 $(86 \%)$ were Italian and $106(14 \%)$ were non-Italians; among this group, $64(8.4 \%)$ were from other European countries, 12 (1.6\%) were from Africa, 21 (2.7\%) from 
Table I. (A) "Importance of olfaction" questionnaire (I0-Q, Croy et al., $2010^{4}$ ); (B) "Importance of taste and flavour" questionnaire (ITF-Q) by our group in the English language with reference to the subscales.
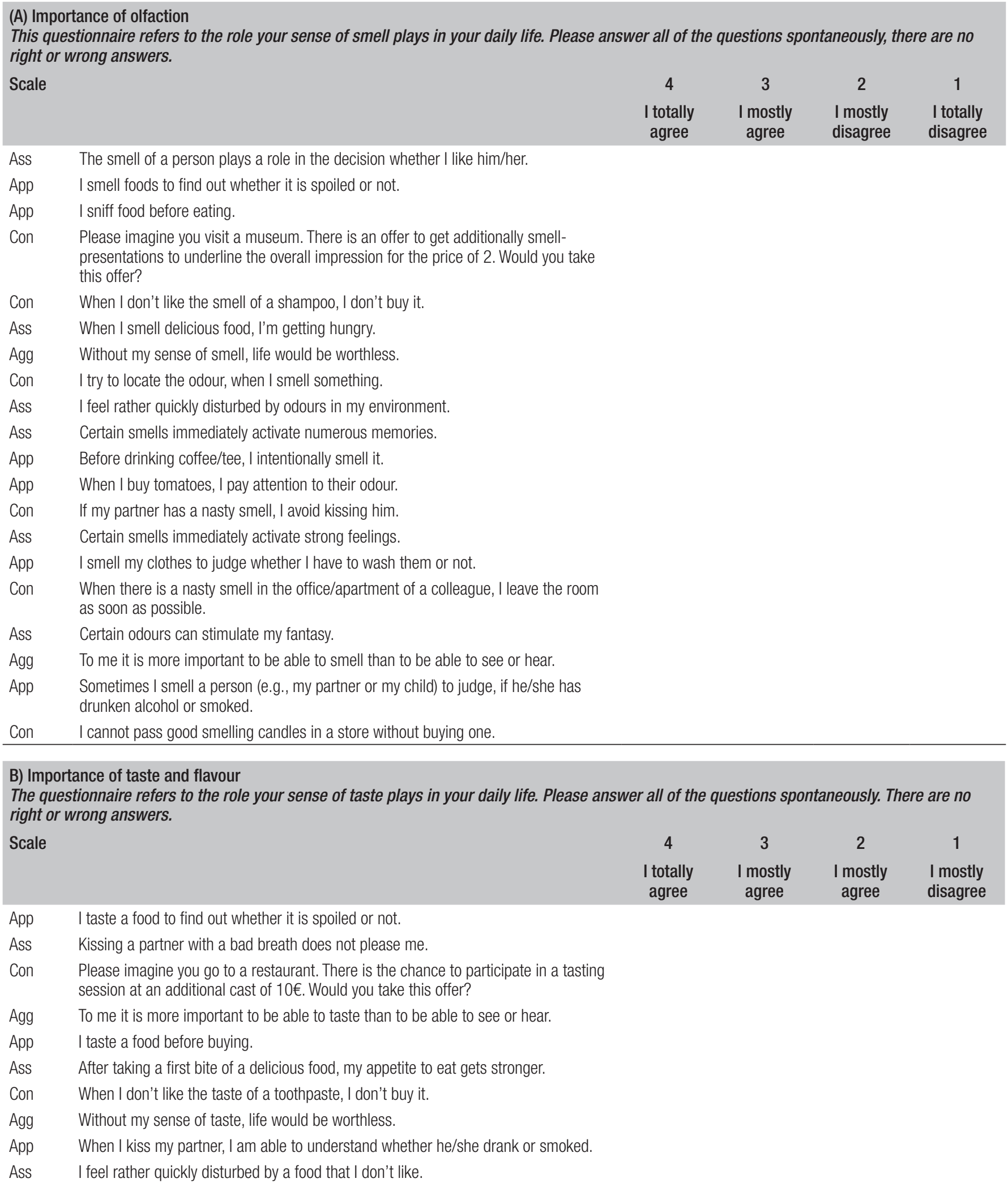
Table I. (B) follows.

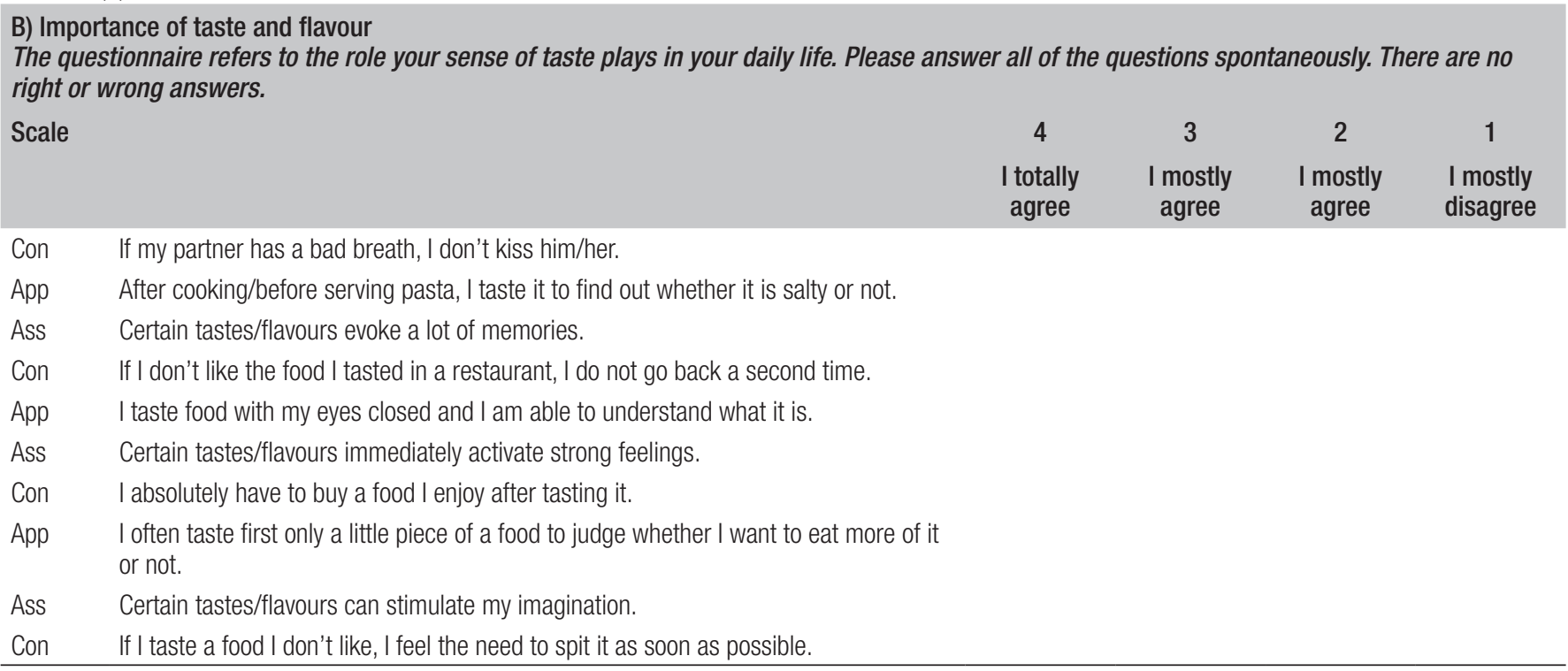

Table II. (A) "Importance of olfaction" questionnaire (IO-Q, Croy et al., 2010 4); (B) "Importance of taste and flavour" questionnaire (ITF-Q) by our group in the Italian language with reference to the subscales.

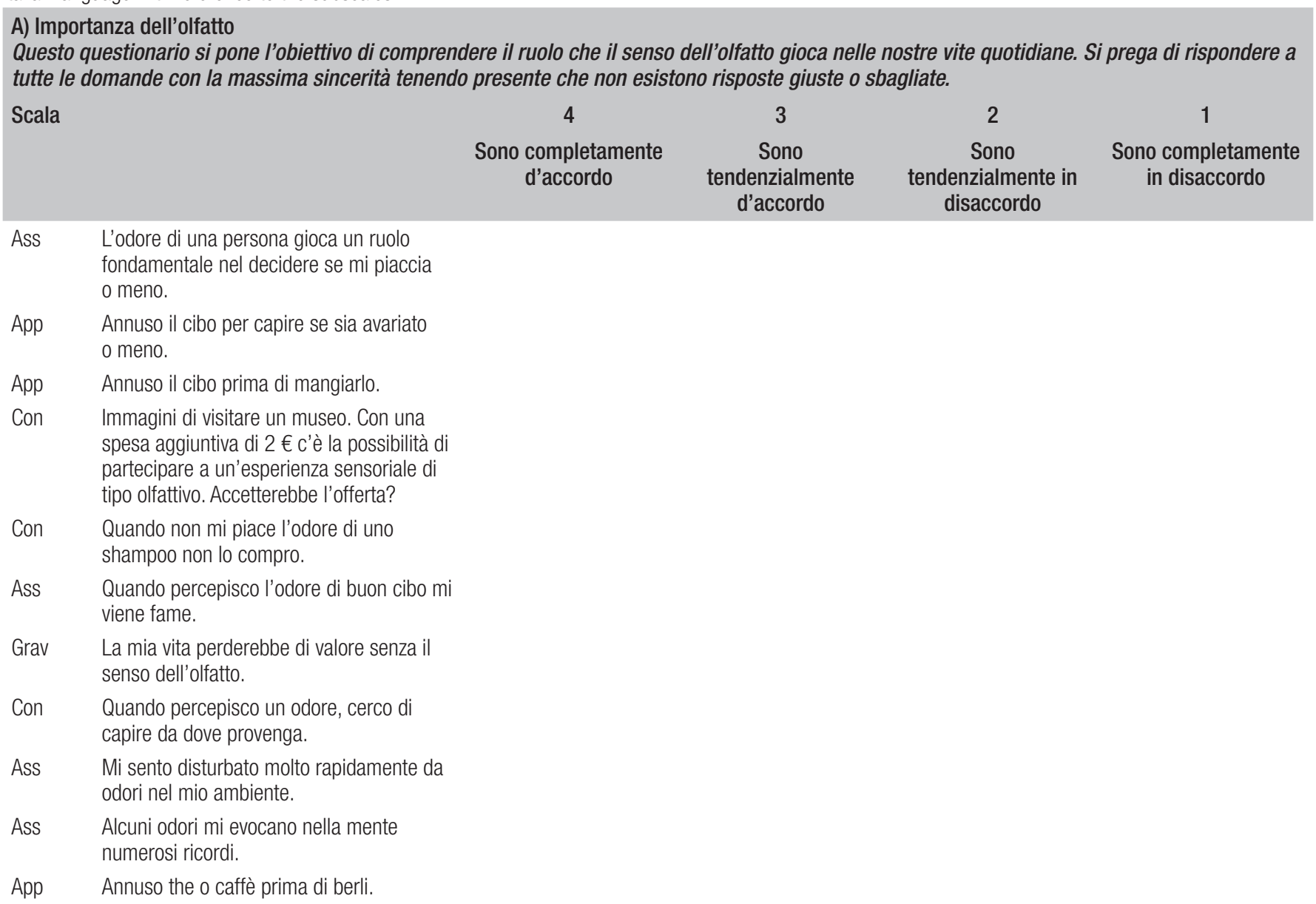


Table II. (A) follows.
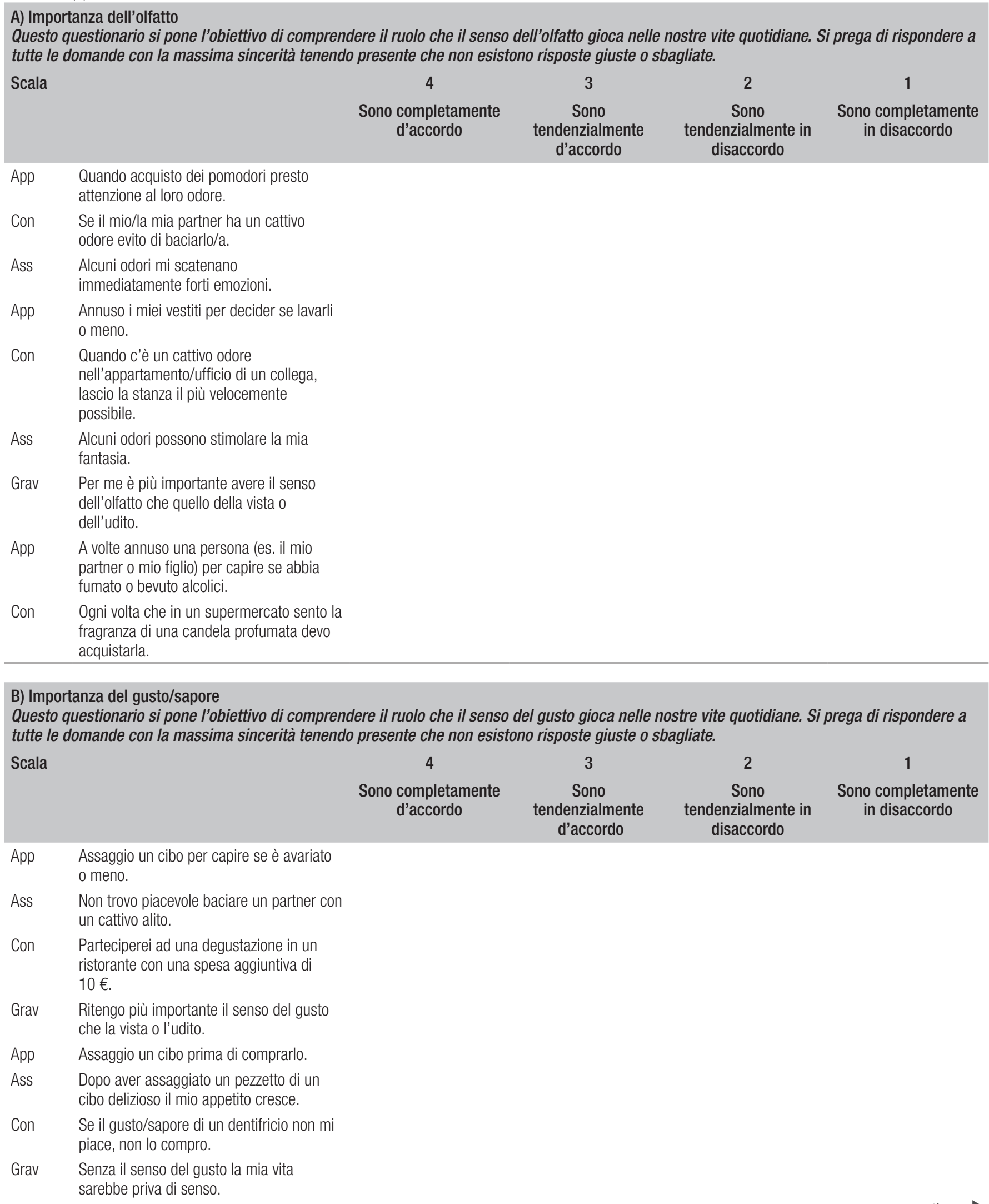
Table II. (B) follows.

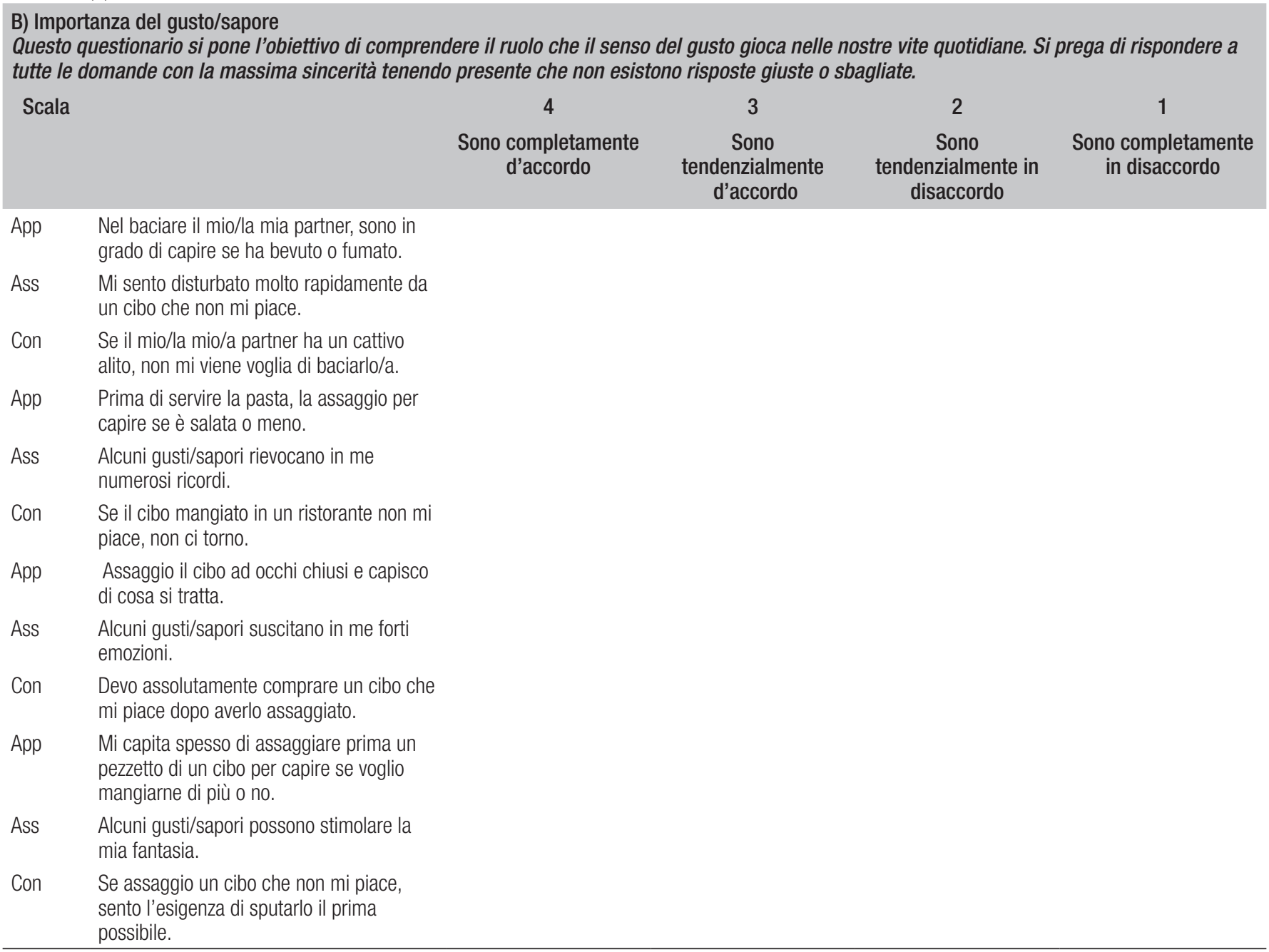

Asia, 7 (0.9\%) from North America and 2 (0.3\%) from South America. The average age was 35.4 years, while the median was 29 (range: 18-80 years).

Figure 1 shows the results on the comparison between average scores. The results revealed that women reported significantly higher scores $(\mathrm{p}<0.05)$ than men in all subscales (association, application, consequence, aggravation) of both questionnaires (IO-Q, ITF-Q). College graduates showed higher scores than high school graduates in every subscale, but the difference between the variables reached significance $(\mathrm{p}<0.05)$ only in two subscales (association in the IO-Q and consequence in the ITF-Q). Lastly, there was a positive and significant correlation (Fig. 2) between age and importance of smell $(r=0.16 ; p<0.01)$ and between age and importance of taste $(r=0.08 ; p<0.05)$.

\section{Discussion}

This study constitutes a preliminary investigation into socio-cultural differences in the importance attributed to sensory perception in the general population, not only regarding olfaction as in previous literature ${ }^{4,11}$, but also with respect to gustatory function.

There appears to be wide variability in the importance that olfactory sensations play in individuals' lives. This variability must be viewed and understood by otolaryngologists and others both in the context of the everyday lives of individuals and in society as a whole. Odours can activate memories, affect social relationships and arouse sexual drive, purchasing decisions and dietary behaviours, and influence our mood and attitude towards being and objects ${ }^{12} 14$. While these findings have scientific support, they are not universally true; nor do they affect all individuals with equal intensity. Clinically, the condition of anosmia 


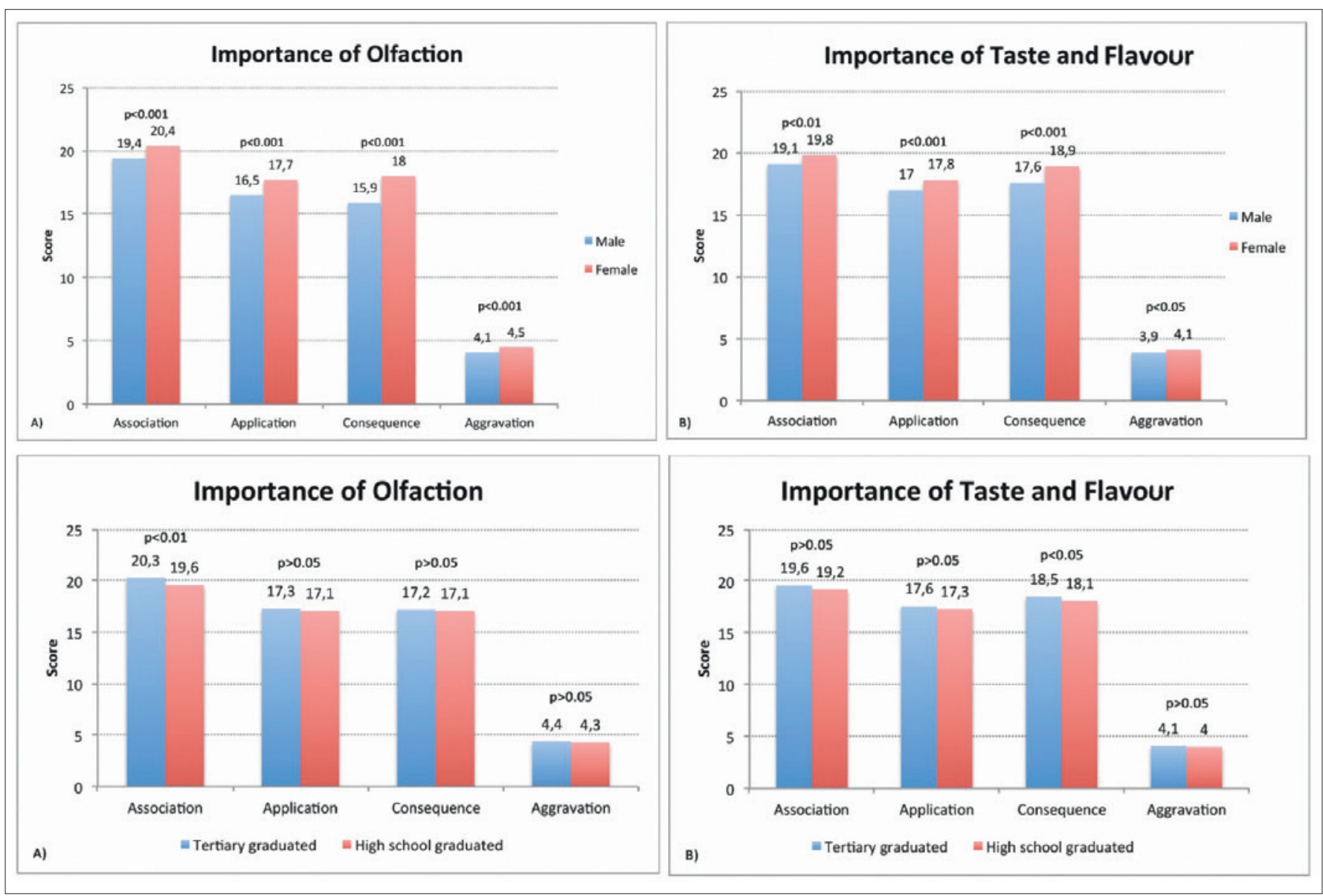

Figure 1. Importance of olfaction (A), taste and flavour (B) in male vs female subjects (upper figure), and in tertiary educated vs high school educated (lower figure).

can be kept private ${ }^{4}$ in contrast with other sensory disorders such as hearing impairment ${ }^{15}$. According to Merkonidis et al. ${ }^{16}$ who published the results from a survey about the characteristics of chemosensory disorders, the greatest number of complaints related to a decrease in eating enjoyment followed by a decrease in overall quality of life. According to Murr et al. ${ }^{11}$, the assessment of the subjective importance of olfaction is useful to examine the adaptation to olfactory disorders. Questionnaires enable systematic and time efficient collection of medical history. Subjective olfactory assessment should not be undertaken in isolation, but can be completed prior to psychophysical assessment of olfactory function (e.g. "Sniffin' Sticks", "University of Pennsylvania Smell Identification Test, UPSIT") or during the waiting time between clinical examinations ${ }^{1,5}$.

However, according to the literature, tests about subjective olfactory importance and coping are still rare and are often performed using visual analogue scales, Likert questionnaires, or as part of other outcome assessments ${ }^{1}$. The only validated, internationally used questionnaire focusing on management of smell impairments is the "Questionnaire of Olfactory Disorders" (QOD) ${ }^{3}$, while the only questionnaires analysing the individual significance of olfaction are the "Odor Awareness Scale" (OAS) ${ }^{17}$ and the "Importance of Olfaction Questionnaire" (IO-Q) ${ }^{4}$. In our opinion, the IO-Q has the advantage of taking only limited clinical time both for patients, who have to answer only 20 items compared to 34 on the OAS, and for consultants who can easily draw conclusions by calculating the scores of the different subscales. Moreover, the changing answer format within the OAS may generate confusion in some participants. The greater comprehensibility and lower redundancy of the IO$\mathrm{Q}$ ensure that respondents answer the entire questionnaire appropriately.

For the reasons noted above, our group preferred to make use of this currently available validated questionnaire. The "ITF-Q", a novel extension of the "IO-Q", is intended to provide a wide gauge of the importance of taste and fla- 

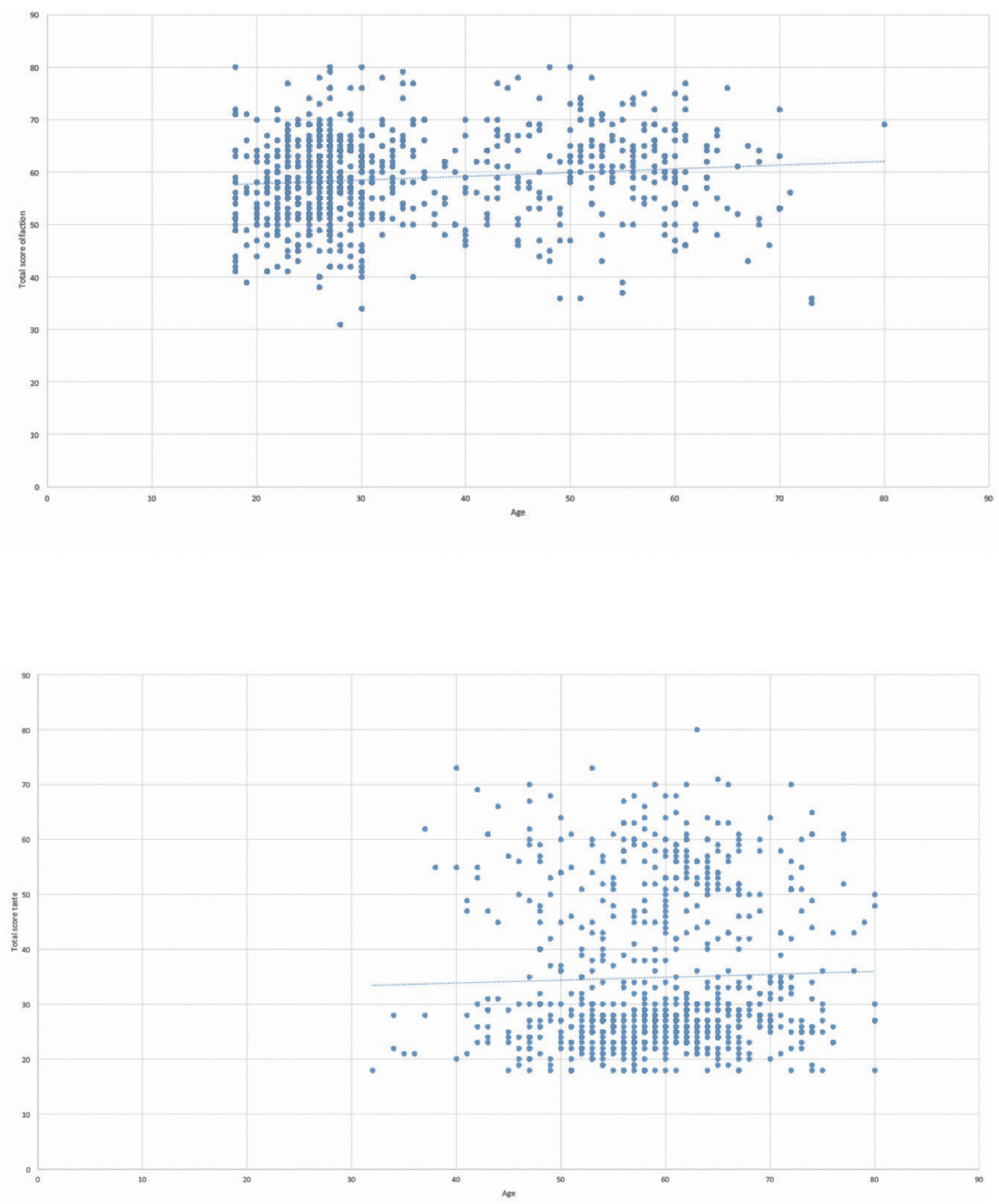

Figure 2. Correlation between total score of the IO-Q and age (upper figure) and between total score of the ITF-Q and age (lower figure). 
vour. To the best of our knowledge, questionnaires on the individual importance of olfaction are rare, but even fewer questionnaires on taste have been published. Thus, following a comprehensive review, we decided to propose the first questionnaire on the importance of taste and flavour. Since specific exams evaluating taste and retronasal smell have been validated (e.g., taste strips, retronasal assessment), tests on the subjective importance of gustatory function should also be performed in combination with psychophysical testing.

Designing and pre-testing a questionnaire on taste and flavour immediately revealed a controversial issue. For nonspecialists, the words "taste" and "flavour" are essentially equivalent, while the term retronasal smell may be unfamiliar. According to the French physical chemist Hervé This, an expert in molecular gastronomy ${ }^{18}$, taste should be considered as a global, synthetic perception, made up of all sensations that a food transmits to us, and which we use to make a judgment. His theory stated that food should stimulate the various sensory receptors involved in vision, odour, taste, trigeminal system and temperature and showed the multisensory experience deriving from our perception of food and drink. Zampini et al. ${ }^{19}$ studied the multisensory perception of flavour, specifically analysing its interaction with visual and auditory stimuli. The authors noted that the average individual believes that the flavour of food primarily comes through the taste buds, ignoring the important "nasal" component in the perception of flavour. For the reasons noted above, we preferred to refer to "taste" and the entire eating experience in our questionnaire, rather than speaking of taste, flavour or retronasal smell in scientific terms ${ }^{20}$.

Analysis of our results indicated that smells, tastes and flavours are more important for women compared to men. This is consistent with a greater sensitivity of women in these areas ${ }^{4,11}$. Secondly, there were no statistically significant differences in importance in these areas between people with different levels of education. Third, the perception of smells, tastes and flavours tends to deteriorate with age; however, their importance does not seem to decrease ${ }^{4}$.

The individual significance of olfaction was investigated by using the IO-Q by Croy et al. who first presented the survey to 123 individuals attending a scientific conference at the University of Dresden ${ }^{4}$ and then compared the importance of olfaction between patients with smell impairment and healthy normosmic subjects. Murr et al. ${ }^{11}$ also used the IO-Q to capture the differences between normosmic and dysosmic individuals. Analysis of our results and those of previous studies reveals that women place higher importance on olfaction than men. Croy et al. in $2010^{4}$ detected this sex-related difference only in the consequence subscale $(\mathrm{p}=0.013)$, while in $2011^{21}$ normosmic control female individuals presented higher scores on the application $(\mathrm{p}=0.003)$ and consequence $(\mathrm{p}<0.001)$ subscales than males. Murr et al. ${ }^{11}$ demonstrated that the importance of olfaction was highest in the group of young normosmic women aged $<26$ years, while there were no sex related significant differences in the other age groups. In our study, we showed an enhanced importance of olfaction in female individuals in each subscale $(p<0.001)$. These results are in accordance with the current literature. The assessment of male physical desirability is highly correlated with the assessment of male body odour attractiveness in women ${ }^{22}$. While olfactory detection thresholds of pregnant women do not seem to be different from those of controls, many women report heightened smell sensitivity during pregnancy ${ }^{23}$. As demonstrated by Minovi et al. ${ }^{24}$, on a clinical level, sex was a predictor of the outcome of nasal surgery in terms of olfactory function with women reporting a significantly higher benefit from surgery $(\mathrm{p}<0.03)$.

Investigating the effects of age, we detected a positive and significant correlation (Fig. 2) between age and the individual importance of olfaction $(r=0.16 ; p<0.01)$. Croy et al. ${ }^{4}$ noticed the absence of significant correlation between age and the importance of olfaction in the main score and in any of the subscales $(r=0.0-0.1)$. The same group ${ }^{21}$ showed no effect of age on IO-Q scores in normosmic control individuals or patients. As previously noted, Murr et al. ${ }^{11}$ found enhanced importance of olfaction in the group of young women, but detected no differences in the other age groups. On the other hand, men did not present any variability in importance of olfaction across the different age groups. These findings appear to fit well with Croy's theory ${ }^{4}$ according to which the importance of olfactory function is independent of age. Decreased olfactory function is very common in the elderly, with the $>50 \%$ of individuals aged 65 and 80 years suffering from it. However, the individual importance of olfaction does not appear to decrease throughout life, probably because of the notable effects of age-related olfactory sensory loss on physical well-being, quality of life, nutritional status and everyday safety ${ }^{25}$. Education-related variability in the individual importance of olfaction was not investigated in the previous study by Croy et al. ${ }^{4}$ in which the IO-Q was used. The conclusions drawn should be interpreted within the limitations of the sample, presenting a high percentage of college graduates (66.9\%) compared to individuals with lower levels of education. In fact, the participating group presented the usual attributes of such voluntary samples, including higher education level ${ }^{4}$ and better awareness of the topic being investigated. However, our results demonstrate that the importance of smell, taste and flavour is the same regardless of 
the cultural background. It is worth noting that our sample scored significantly highest the association scale, which is related to memories, feelings and judgments guided by the sensory perception ${ }^{4}$. These findings are consistent with the finding that the olfactory pathway is a portion of the palaeocortex, the oldest part of the brain, which generates emotions and accounts for memory. Perception of olfactory sensations is emotionally influenced ${ }^{26}$; it is ancestral and deeper than the educational and cultural levels of individuals. Moreover, other parameters (i.e., work conditions, hobbies, environments) may modify individual olfactory sensitivity, especially in an era in which great attention is given by media to odour and food culture. For example, perfumers tend to respond more sensitive to odours ${ }^{27}$ and working in perfume retail shops is associated with increased odour discrimination ${ }^{28}$. The present study is limited by not having investigated the odour expertise of the subjects included, while behavioural studies on this topic are warranted.

Even though Croy et al. ${ }^{4}$ encouraged the use of the IO-Q to study cross-cultural variability in the perception in greater depth, the current and previous literature has not analysed country-related differences in the importance of chemosensation. Our sample had more Italians than individuals from other countries (Italians: 653; non-Italians 106). As a result, it should be noted that a response bias might be present, and this limitation prevented us from studying country-related variability. However, this remains a very interesting topic and further studies by Otolaryngology societies worldwide should be undertaken in order to better understand the factors behind socio-cultural variability in perception. The individual significance attributed to taste and flavour has not been widely discussed in the existing literature; consequently, we encourage the use of the ITF$\mathrm{Q}$, in order to confirm or invalidate our results.

Regarding the strengths and limitations of our study, we introduced a new tool to investigate the subjective importance of sensory importance and used it on a rather large sample of 759 subjects with heterogeneous characteristics. However, our research may be limited by issues of validity associated with email surveys, which can be subject to considerable bias ${ }^{6}$. Although such criticism may be appropriate, Internet and Web-based research may be useful to get pilot data. Another limitation of the present study is the lack of correlation of subjective results with objective measurements. The next step in this research would be to perform an investigation using questionnaires in patients with olfactory or gustatory disorders, while describing their causes of sensory impairment and comparing the results with those of a control group. Moreover, in a further experiment, we plan to establish the relationships that exist between the subjective results of the questionnaire with those of psychophysical testing of olfactory and gustatory function and to improve the accuracy of our data. Lastly, an interesting point for future research would be to evaluate the types of diets and feeding behaviours of the population and investigate if they have any relationships with the importance attributed to smell and taste.

\section{Conclusions}

We propose a novel test that provides insight into the importance of smell, taste and flavour among individuals as well as socio-cultural differences. Although further research is needed, this new tool revealed preliminary useful information about the importance of smell, taste and flavour. In a wider context, it could help in the evaluation and investigation of the aspects that influence patients to seek medical attention in the presence of sensory alterations ${ }^{29}$.

\section{Acknowledgements}

This work was presented as a scientific poster presentation at the $64^{\text {th }}$ Annual Meeting of the American Rhinologic Society (ARS), Atlanta (Georgia), on October 5-6, 2018.

We thank Prof. Thomas Hummel and Dr. Saul Strieb for their constant support and their comments, which greatly improved this manuscript.

\section{References}

1 Hummel T, Whitcroft KL, Andrews P, et al. Position paper on olfactory dysfunction. Rhinology 2017;54:1-30. https://doi.org/10.4193/ Rhino16.248

2 Erskine SE, Hopkins C, Clark A, et al. SNOT-22 in a control population. Clin Otolaryngol 2017;42:81-85. https://doi.org/10.1111/ coa. 12667

3 Frasnelli J, Hummel T. Olfactory dysfunction and daily life. Eur Arch Oto-Rhino-Laryngology 2005;262:231-235. https://doi.org/10.1007/ s00405-004-0796-y

4 Croy I, Buschhüter D, Seo H-S, et al. Individual significance of olfaction: development of a questionnaire. Eur Arch Oto-Rhino-Laryngology 2010;267:67-71. https://doi.org/10.1007/s00405-009-1054-0

5 Nordin S, Brämerson A, Murphy C, et al. A Scandinavian adaptation of the multi-clinic smell and taste questionnaire: evaluation of questions about olfaction. Acta Otolaryngol 2003;123:536-542. https:// doi.org/10.1080/00016480310001411

6 Eysenbach G. Improving the quality of web surveys: the Checklist for Reporting Results of Internet E-Surveys (CHERRIES). J Med Internet Res 2004;6:e34. https://doi.org/10.2196/jmir.6.3.e34

7 Crum RM, Anthony JC, Bassett SS, et al. Population-based norms for the Mini-Mental State Examination by age and educational level. JAMA 1993;269:2386-2391. http://www.ncbi.nlm.nih.gov/ pubmed/8479064

8 Gallo S, Russo F, Mozzanica F, et al. Prognostic value of the Sinonasal Outcome Test 22 (SNOT-22) in chronic rhinosinusitis. Acta Otorhinolaryngol Ital 2020;40:113-121. https://doi. org/10.14639/0392-100X-N0364 
9 Vennemann MM, Hummel T, Berger K. The association between smoking and smell and taste impairment in the general population. J Neurol 2008;255:1121-1126. https://doi.org/10.1007/ s00415-008-0807-9

10 Beaton DE, Bombardier C, Guillemin F, et al. Guidelines for the process of cross-cultural adaptation of selfreport measures. Spine 2000;25:3186-3191. https://doi. org/10.1097/00007632-200012150-00014

11 Murr J, Hummel T, Ritschel G, et al. Individual significance of olfaction: a comparison between normosmic and dysosmic people. Psychosomatics 2018;59:283-292. https://doi.org/10.1016/j. psym.2017.11.009

12 Gudziol V, Wolff-Stephan S, Aschenbrenner K, et al. Depression resulting from olfactory dysfunction is associated with reduced sexual appetite - a cross-sectional cohort study. J Sex Med 2009;6:19241929. https://doi.org/10.1111/j.1743-6109.2009.01266.x

13 Aschenbrenner K, Hummel C, Teszmer K, et al. The influence of olfactory loss on dietary behaviors. Laryngoscope 2008;118:135-144. https://doi.org/10.1097/MLG.0b013e318155a4b9

14 Croy I, Nordin S, Hummel T. Olfactory disorders and quality of life-an updated review. Chem Senses 2014;39:185-194. https://doi. org/10.1093/chemse/bjt072

15 Mick P, Kawachi I, Lin FR. The association between hearing loss and social isolation in older adults. Otolaryngol Neck Surg 2014;150:378384. https://doi.org/10.1177/0194599813518021

16 Merkonidis C, Grosse F, Ninh T, et al. Characteristics of chemosensory disorders - results from a survey. Eur Arch Otorhinolaryngol 2015;272:1403-1416. https://doi.org/10.1007/s00405-014-3210-4

17 Smeets MAM, Schifferstein HNJ, Boelema SR, et al. The odor awareness scale: A new scale for measuring positive and negative odor awareness. Chem Senses 2008;33:725-734. https://doi.org/10.1093/ chemse/bjn038

18 This H. Food for tomorrow? EMBO Rep 2006;7:1062-1066. doi:10.1038/sj.embor.7400850
19 Zampini M, Spence C. Assessing the role of visual and auditory cues in multisensory perception of flavor. In: Murray MM, Wallace MT, editors. The Neural Bases of Multisensory Processes. Boca Raton (FL): CRC Press/Taylor \& Francis; 2012. Chapter 37.

20 Pandurangan M, Hwang I. Systemic mechanism of taste, flavour and palatability in brain. Appl Biochem Biotechnol 2015;175:3133-3147. https://doi.org/10.1007/s12010-015-1488-3

21 Croy I, Landis BN, Meusel T, et al. Patient adjustment to reduced olfactory function. Arch Otolaryngol Head Neck Surg 2011;137:377382. https://doi.org/10.1001/archoto.2011.32

22 Craig Roberts S, Little AC, Lyndon A, et al. Manipulation of body odour alters men's self-confidence and judgements of their visual attractiveness by women. Int J Cosmet Sci 2009;31:47-54. https://doi. org/10.1111/j.1468-2494.2008.00477.x

23 Cameron EL. Pregnancy and olfaction: a review. Front Psychol 2014;5:1-11. https://doi.org/10.3389/fpsyg.2014.00067

24 Minovi A, Hummel T, Ural A, et al. Predictors of the outcome of nasal surgery in terms of olfactory function. Eur Arch Otorhinolaryngol 2008;265:57-61. https://doi.org/10.1007/s00405-007-0409-7

25 Attems J, Walker L, Jellinger KA. Olfaction and aging: a mini-review. Gerontology 2015;61:485-490. https://doi.org/10.1159/000381619

26 Walliczek-Dworschak U, Hummel T. The human sense of olfaction. Facial Plast Surg 2017;33:396-404. https://doi. org/10.1055/s-0037-1603828

27 Royet J-P, Plailly J, Saive A-L, et al. The impact of expertise in olfaction. Front Psychol 2013;4:928. https://doi.org/10.3389/ fpsyg.2013.00928

28 Hummel T. Olfactory sensitivity of subjects working in odorous environments. Chem Senses 2004;29:533-536. https://doi.org/10.1093/ chemse/bjh058

29 Marchese-Ragona R, Restivo DA, De Corso E, et al. Loss of smell in COVID-19 patients: a critical review with emphasis on the use of olfactory tests. Acta Otorhinolaryngol Ital 2020;40:241-247. https:// doi.org/10.14639/0392-100X-N0862 